\title{
Crisis del sistema humanitario en Chile. Refugiadas colombianas deslegitimadas en la frontera norte ${ }^{1}$
}

\author{
Crisis of the humanitarian system in Chile. Colombian refugees delegitimized on \\ the northern border
}

\author{
Nanette Liberona Concha ${ }^{2}$ y Evelyn López San Francisco ${ }^{3}$
}

\section{Resumen}

El ańo 2007 se instala el Programa de Refugio en Iquique, debido al aumento de solicitudes en la región de Tarapacá. En 2010 se dicta la Ley de Refugio en Chile, no obstante, a partir de entonces, tanto las solicitudes de asilo como las concesiones de protección comienzan a disminuir, alcanzando cifras irrisorias en 2012. Nuestra participación en el Programa Refugio y un Diagnóstico Participativo con mujeres colombianas solicitantes de refugio, han dilucidado algunos aspectos. Se identifica que en la región existe una instancia preliminar al proceso de solicitud de asilo, de "pre- admisibilidad". El ingreso irregular es un motivo determinante para la inadmisibilidad al proceso. El principal factor que justifica el ingreso irregular a Chile es la negación del ingreso por la vía institucionalizada. Como consecuencia, los solicitantes de asilo no admitidos en el proceso optan por la permanencia clandestina en el país. Quienes son reconocidos como solicitantes o refugiados quedan sujetos al asistencialismo desmovilizador del sistema humanitario internacional o al desconocimiento de su condición por parte de instituciones claves y de la comunidad en general, situación que se traduce en discriminación y racismo. Nos preguntamos entonces, ¿por qué se produce tal deslegitimación del refugio en Iquique? ¿Qué motiva a las mujeres colombianas a permanecer en un lugar donde son maltratadas y humilladas? ¿En qué se relacionan, en este contexto, refugiados e inmigrantes? Un análisis de la crisis del sistema humanitario internacional nos ayudará a responder a estos cuestionamientos.

Palabras claves: refugiados, ingreso irregular, asistencialismo, racismo, derechos humanos.

\begin{abstract}
In 2007, the Refugee Program in Iquique is installed due to the increased numbers of applications in the region of Tarapaca. In 2010, the Refugee Act is launched in Chile, nonetheless, thereafter; both applications for refugee status and concessions for protection begin to decrease, reaching a derisory figure in 2012. Given the participation of the authors in the Refugee Program and a participatory diagnostic with refugee women applicants, it has been elucidated some aspects about the process. It is identified that in the region there is a "pre admissibility" instance, preliminary to the refugee application process. The irregular entrance of the refugees is a determining reason for inadmissibility status to the process. The main factor that tends to the irregular entrance is the denial of the entry to Chile. As a result, people not admitted in the process, choose for staying illegally/clandestine in the country. Whom that are recognized as requestors or refugees, stay subjects to the demobilized assistance of the international humanitary system or to the lack of awareness toward the refugee status by the key institutions and comunity in general, situation that results in discrimination and racism. So, we wonder $¿$ why is it produced that delegitimization of refugees in Iquique? ¿what are the reasons that the colombian womens had to stay in a place where they are abused and humiliated? ¿in which way are related refugees and inmigrants in this context? An analysis of the crisis of the internacional humanitary system will help us to answer these questions.
\end{abstract}

Keywords: refugees, irregular entrance to a country, assistance, racism, human rights.

Recibido: 22 agosto 2016. Aceptado: 26 abril 2017

1 Trabajo realizado a partir de la experiencia de práctica profesional de Evelyn López San Francisco para optar al grado académico de Licenciada en Trabajo Social por la Universidad Arturo Prat. "Aprendizajes logrados en el Programa Refugio-Iquique. Un análisis de la política pública en Chile, años 2011-2012".

2 Instituto de Estudios internacionales INTE, Universidad Arturo Prat. Av. Arturo Prat 2120, Iquique, CHILE. Email: nliberonac@gmail.com

3 Universidad Arturo Prat, Av. Arturo Prat 2120, Iquique, CHILE.

Email: evel.lopez@hotmail.com 


\section{Introducción}

Tal como lo señala el título del presente artículo, la pregunta que motiva esta investigación surge al constatar la disminución del número de refugiados en Iquique y el desconocimiento del refugio por parte de la sociedad iquiqueña en la región de Tarapacá. ¿Por qué la condición de refugiado se deslegitima en circunstancias en que se promulga una Ley de Refugio acorde a los estándares internacionales de protección humanitaria? Esta disonancia nos llevó a identificar dos problemáticas que desarrollaremos y explicaremos en el presente artículo, para lograr responder nuestras interrogantes. La primera, que se desprende de lo que sucede a nivel local, se refiere al peso de la Ley de Extranjería, Decreto Ley 1094 de 1975 y de lo que significa ser extranjero en Chile, y más aún ser un "otro" estigmatizado, como lo son las poblaciones de apariencia "negra" (Tijoux, 2014; Tijoux y Palominos, 2015; Tijoux (Ed.), 2016). Intentaremos demostrar que el desconocimiento de la Ley de Refugio por parte de funcionarios públicos que controlan el ingreso a Chile y la implementación de un proceso alegal a nivel regional para la selección de solicitantes de asilo son consecuencias de la vigencia de la doctrina de la seguridad nacional y de una cultura racista. A esto se suma el desprestigio social de la condición de refugiado, lo que revela la falta de políticas integrales de acogida hacia la migración forzada en Chile, en particular cuando ponemos atención al maltrato y humillaciones de las que son víctimas estas personas en la vida cotidiana. La segunda problemática, de carácter global, responde a una interrogante que se desprende de la principal y apunta a saber en qué se relacionan, en este contexto, refugiados e inmigrantes. En este sentido, este caso se presenta como una demostración más de la crisis del sistema internacional de protección humanitaria. Cuestionaremos el actual funcionamiento de este sistema, sobre todo al constatar lo difícil que resulta hoy en día disociar la migración económica del refugio. Las migraciones de Colombia son ejemplares al dar cuenta de la crisis multidimensional $^{4}$ que afecta a amplios sectores de la

4 "Esto se corresponde con datos que describen la crisis económica de fines del siglo XX como la más fuerte que se haya vivido en el país, situación ya experimen- sociedad colombiana, haciendo que los estudios sobre esta población se enfoquen en los nexos entre las diversas categorías de movilidad, habitualmente disociadas.

Antes de entrar en materia, es importante señalar que este trabajo es fruto de la práctica profesional como trabajadora social de la coautora del manuscrito, quien ejerció funciones en el Programa Refugio durante cuatro años. La sistematización de esta experiencia fue analizada e interpretada por la autora principal desde la perspectiva de las relaciones interétnicas, mediante técnicas de análisis cualitativo, complementadas con dos entrevistas en profundidad a funcionarias del programa, revisión de documentos y de la literatura especializada. Tomaremos además los resultados de un Diagnóstico Participativo, "realizado con el fin de conocer mejor la situación de los y las refugiadas y solicitantes de refugio, y de darles la posibilidad de expresar sus preocupaciones y emociones". Éste fue organizado el 30 de septiembre de 2011 en la ciudad de Iquique. La metodología utilizada fue la de grupos de discusión, separados por sexo. La mayoría de los y las participantes fueron afrodescendientes, de entre 13 y 45 ańos, que ingresaron a Chile a partir del ańo 2009. Los temas tratados fueron diferenciados en relación a los riesgos asociados al ingreso en la frontera; el acceso a los trámites de refugio, acceso a los servicios y calidad de los mismos, estigma y discriminación, considerando las necesidades específicas de hombres y mujeres. Se trabajó con facilitadores de ACNUR, funcionarios/

tada en otras naciones latinoamericanas: entre 1999 y 2000 se registró una disminución de 4,5\% del PIB, el desempleo alcanzó el 19,5\%, el déficit fiscal llegó a ser de $5,5 \%$ y los despidos generalizados de empresas, el descenso acelerado del nivel de vida de las clases medias y el mayor empobrecimiento de los sectores populares fueron algunas de sus consecuencias (Gamarra, 2004, p. 45). Al lado de esto se presenta una exacerbación del conflicto armado, un conflicto multicausal con profundas raíces históricas y con diversas expresiones territoriales y del que participan guerrillas, paramilitares, narcotraficantes, empresas multinacionales y sectores del Estado, y que tiene como uno de sus resultados el incremento de las condiciones de inseguridad para la sociedad civil, expresado, entre otras cosas, en acciones como el secuestro, la extorsión, las masacres y los asesinatos colectivos" (Villa, 2009, p. 16). 
as de los programas, apoyados/as por estudiantes en práctica. Aquí consideramos los resultados de uno de los grupos e insertaremos extractos de los registros para fortalecer los planteamientos. Del universo de personas invitadas, se consideró a 30 mujeres, pero solo nueve asistieron, muchas se excusaron por no tener la autorización de sus empleadores. Todas fueron mujeres colombianas solicitantes de refugio, entre las cuales siete son afrodescendientes, originarias de Buenaventura y dos mestizas, provenientes de Cali. ${ }^{5}$

Para contextualizar el caso de estudio, en este artículo se presentarán, en primera instancia, algunos antecedentes sobre el sistema internacional de protección humanitaria y específicamente los marcos jurídicos latinoamericanos y chilenos. Se discutirá, además, la vigencia y predominancia de la Ley de Extranjería y sus fundamentos ideológicos, así como las categorías de "extranjero" y "negro", dentro del sistema de percepciones y categorizaciones sociales en Chile; se levantará asimismo un breve estado de la cuestión de la migración forzada en Chile. En el segundo apartado, se expondrá la disminución de la admisibilidad al proceso de solicitud de refugio y las principales consecuencias que tiene la crisis del sistema humanitario internacional en Chile. En el tercer apartado se presentarán las características de los y las solicitantes y refugiados/ as, luego el funcionamiento del Programa Refugio en Iquique, así como los problemas revelados en la intervención y en la experiencia de esta población en Iquique. Esto se realizará a través de las voces de las mujeres que participaron en el Diagnóstico Participativo. Se cerrará el artículo con unas reflexiones que se desprenden de lo anteriormente expuesto, retomando las dos problemáticas presentadas, desde lo local a lo internacional. Éstas nos llevan a plantear la necesidad de transformaciones profundas en las políticas migratorias, en la actual coyuntura histórica y política, que es propicia para abordar la temática en el país.

5 "Si bien el total de las solicitudes de asilo presentadas en Chile muestra un predominio masculino, las peticiones registradas en el norte corresponden mayoritariamente a mujeres" (Courtis, 2012, pp. 163-164).

\section{El sistema humanitario internacional y la migración forzada hacia Chile}

Es una evidencia que el sistema de protección humanitaria internacional ha cumplido un rol significativo a nivel mundial, siendo el trabajo realizado por el ACNUR otorgar protección internacional a hombres, mujeres, niños y niñas que se ven obligados a migrar de sus países de origen, con el fin de salvar sus vidas. No obstante, algunos autores cuestionan el sistema humanitario internacional por considerarlo un paliativo que permite continuar con la intervención de potencias económicas en países periféricos (Agier, 2006). En alusión a lo planteado por Bourdieu en el apartado "La démission de l'État" de la gran obra La misère du monde (1993, pp. 219-228), Agier asocia la intervención humanitaria a la "mano izquierda del imperio", que no cesa de reparar los dańos sociales y culturales de una "mano derecha", formada -siguiendo a Bourdieu- por administradores que aplican los principios económicos de rentabilidad y retorno de la inversión a la gestión pública. Es más, Agier se refiere al "mundo humanitario como ficción totalitaria", debido a las muchas denuncias y abusos que se han producido, en particular sobre el manejo de la acción política en los campos de refugiados (en África, Oriente Próximo y Asia). Su tesis se basa en la noción de persona construida por la antropología a partir del proceso de individuación, conformado por la identidad entre la parte observada (observación participante) y el todo que no se ve jamás, pero que llamamos "sociedad" o "cultura". La individuación permitiría comprender que el individuo está atrapado en las restricciones de poderes y de sentidos de la sociedad en la que existe, aterrorizado por la fuerza de los jefes y la interpretación de los sacerdotes (chamanes, brujos, etc.), pudiendo asociarlo, como lo hace Marc Augé, al "totalitarismo del linaje". Agier asocia la organización social y política de los campos de refugiados a las estructuras de parentesco, ambos considerados como espacios totalitarios (Agier, 2006, p. 4).

Por otra parte, los impactantes desbordamientos de refugiados sirios y la decisión europea de contención han demostrado la crisis del sistema humanitario 
internacional. ${ }^{6}$ Crisis que ha sido descrita igualmente por investigadores/as que han trabajado la migración forzada colombiana, en investigaciones que abordan las problemáticas del desplazamiento forzado al interior del mismo país y su relación con el refugio transfronterizo hacia Ecuador y Venezuela (A. González, 2015; Naranjo, 2015; Riaño, 2009; Valenzuela, 2009; Villa, 2009, entre otros). Investigaciones en las que se destaca que las razones para cruzar las fronteras son generalmente al mismo tiempo económicas y de conflicto; también denuncian la incapacidad de las sociedades receptoras de generar condiciones adecuadas de acogida. La vulnerabilidad en la que se encuentran generalmente los y las solicitantes de asilo y refugiados/as da cuenta del fracaso de la protección humanitaria, un sistema que surge a mediados del siglo XX mediante un acuerdo internacional que instala la idea de una nueva era, de cooperación y libre de racismo. De igual manera, hablar de migración forzada es también hablar de las consecuencias del modelo económico y político global, es decir, la permanente violación de derechos humanos de amplias mayorías en el mundo.

Sumiéndonos en el marco jurídico, observamos que, a diferencia de los primeros instrumentos internacionales de protección que se crearon en materia de refugio, la Convención de $1951^{7}$ conceptualiza la expresión de refugiado, dándole un enfoque más subjetivo y de ventaja básicamente individual. Desde la mirada tradicional, lo realmente fundamental era la desprotección por parte del Estado de origen y el carácter forzoso del exilio. Pero la expresión de-

6 "Las claves del acuerdo entre la UE y Turquía para la contención de los refugiados ", en ABC Internacional, España. En línea: http://www.abc.es/internacional/ abci-claves-acuerdo-entre-y-turquia-para-contencionrefugiados-201603181720_noticia.html Organismos de Derechos Humanos han criticado el pacto, calificándolo como una expulsión forzada de extranjeros que viola el derecho internacional.

7 La Convención sobre el Estatuto de los Refugiados (ONU, 1951) indica que se considera en situación de refugio a la persona que "por fundados temores por persecución ya sea por raza, religión, nacionalidad, pertenencia a determinado grupo social, a una opinión política, se encuentra fuera del país de su nacionalidad y no pueda o a causa de dichos temores no quiere acogerse a la protección de tal país". finitiva es, entonces, el estado de ánimo, es decir, el miedo a ser perseguido, contenido en una serie de causas evaluadas y localizadas, que en un sentido amplio se identifican con motivos políticos. En el ámbito latinoamericano, se firma la Declaración de Cartagena sobre los Refugiados (ACNUR, 1984) como resultado del "Diálogo sobre la Protección Internacional de los Refugiados en América Central, México y Panamá: Problemas Jurídicos y Humanitarios", celebrado en Cartagena de Indias (Colombia) en noviembre de 1984. La conclusión a la que se llega apela expresamente a la Convención de la OUA y a la doctrina de la Comisión Interamericana de Derechos Humanos, y sostiene que:

\section{[...] la definición o concepto de refugiado recomendable para su utilización en la re- gión es aquella que, además de contener los elementos de la Convención de 1951 y el Protocolo de 1967, considere también como refugiados a las personas que han huido de sus países porque su vida, seguridad o li- bertad han sido amenazadas por la violen- cia generalizada, la agresión extranjera, los conflictos internos, la violación masiva de los derechos humanos u otras circunstancias que hayan perturbado gravemente el orden público.}

En la práctica, varios de los países del continente cuentan con nuevos estatutos de protección diferenciados del refugiado, bajo calificaciones especiales como refugio humanitario, protección temporal o figuras subsidiarias de protección. Como es lógico, las características concretas pueden variar de un Estado a otro, no obstante cabe identificar algunos rasgos comunes en todos ellos: ${ }^{8}$ en primer lugar, su naturaleza habitualmente extralegal y altamente informal, como consecuencia de su escasa o nula regulación normativa. En segundo lugar, su configuración de carácter enormemente discrecional, tanto en lo que se refiere a la decisión de concesión de protección -generalmente poco transparente y huérfana de control judicial- como al contenido de la protección otorgada. $Y$ en tercer

8 Al respecto, entre otras contribuciones. Berger, N. La politique européenne d'asile et d'immigration. Enjeux et perspectives. Bruxelles: Bruylant, 2000, p. 201. 
lugar, el considerable debilitamiento de los estándares de protección, configurándose así como un estatuto más provisional, en tanto que orientado plenamente a la repatriación, y menos costoso para el Estado de acogida, al implicar generalmente menores derechos socioeconómicos.

El Estado chileno busca ponerse a la vanguardia en la región, dictando el año 2010 la Ley 20.430, conocida como Ley de Refugio, a través de la cual se entregan las garantías que establecen los protocolos de protección al asilo internacional. Hasta antes de 2010, el refugio se encontraba regulado por la Ley de Extranjería, que establece un procedimiento para determinar la condición de refugiado a las personas que lo soliciten. Uno de los principios que fundamenta la nueva ley es brindar protección a migrantes forzados que lo requieran, garantizando el derecho a vivir en paz y tranquilidad, tal como lo establece la Constitución Política del país para toda la población chilena, reafirmando el derecho fundamental de las personas a buscar y recibir asilo. Destaca además la importancia del principio pro homine, en el uso de las normas y principios. Esta rama del derecho internacional fortalece la protección internacional de los refugiados, reconociendo el principio de no devolución, que incluye el no rechazo en la frontera.

Contemplado en la Ley 20.430, el principio de non refoulement o no devolución es considerado la piedra angular de este tipo de protección internacional. En efecto, un refugiado o solicitante de esta condición no puede ser expulsado o devuelto bajo cualquier fórmula al país donde su vida, seguridad o libertad corren peligro, pues la institución faltaría a todo principio. Solo se procederá a la expulsión de un refugiado del territorio nacional basado en razones de seguridad nacional o de orden público, ambas contempladas en la Convención de 1951. Es importante destacar que la nueva ley considera los problemas que han enfrentado los refugiados en los pasos fronterizos, manifestando la imposibilidad de expulsar a las personas que, habiendo ingresado de forma irregular, ameritan demandar protección al país. ${ }^{9}$

9 En Chile, frente al rechazo en las fronteras, el ingreso irregular termina siendo uno de los recursos al que optan los migrantes forzados, con todos los riesgos que
Por tanto, en el marco de la nueva legislación, mientras la persona se encuentra solicitando el asilo, se despenaliza el ingreso clandestino. El principio de no sanción por ingreso clandestino o residencia irregular debe ser implementado teniendo como requisito la presentación ante la autoridad correspondiente dentro de los 10 días seguidos a la infracción. Esto debe ser estudiado por una comisión que asesora al subsecretario del Interior, quien tiene que resolver según las solicitudes correspondientes. Si el o la solicitante no logra ser considerado/a refugiado/a, esta condición se inhabilita y será indicado/a como "extranjero infractor", sujeto a firma, hasta que proceda su expulsión.

Otro contenido sustancial de la ley vigente es el reforzamiento de las redes institucionales, para lo cual se establecen derechos y deberes, el fomento de la integración mediante la incorporación de los refugiados a programas sociales; de esta manera se determina el acompańamiento de los organismos del Estado y la sociedad civil. Los y las solicitantes de asilo, refugiados y sus familias tienen derecho a salud, educación, vivienda y trabajo, ya sea en condiciones de trabajador dependiente o por cuenta propia, en igualdad de condiciones que los demás extranjeros.

Por su parte, el Departamento de Extranjería (DEM) es la administración encargada de otorgar el asilo o conceder la protección a los refugiados.

ello conlleva, desde un punto de vista legal y de seguridad personal y pone en evidencia la desprotección frente a los grupos de "coyotes" que operan en las zonas fronterizas. Esto ha sido denunciado por Courtis en una compilación publicada por organismos de las $\mathrm{Na}$ ciones Unidas: "Buena parte de los ingresos se da por la frontera norte, con frecuencia por pasos no habilitados y vinculados a redes de tráfico de personas" (Courtis, 2012, p. 163). Tales problemas fueron señalados en el Diagnóstico Participativo por las mujeres colombianas: "Por Colchane, me demoré ocho dias en entrar, esperando casi sin plata, pasando hambre y frio, éramos varios y juntamos todos el dinero de todos para poder vivir" (María, 59 años). También comentan que fueron maltratadas en la frontera, con una especial connotación racista: "Traté de ingresar regular, pedi refugio, pero me dijo que eso no se daba ya en Chile... no me dejaron por no tener bolsa de viaje y por ser negra, fue asi como me lo dijo el policía: 'Tú, negra, no entras a mi pais'... Me pedia bolsa de viaje de mil dólares. Yo ingresé irregular..." (Betty, 36 años). A propósito de la "bolsa de viaje”, ver Liberona, 2015b. 
Su último anuario (DEM, 2016) señala que entre los años 2005 y 2014, el año 2008 fue el que presentó mayor cantidad de solicitudes (1061 solicitudes). Geográficamente, las solicitudes se concentran en la región Metropolitana (63,8\%), y en las regiones fronterizas del extremo norte, de las cuales Tarapacá representa un $7,7 \%$. A su vez, el anuario destaca que los solicitantes de Colombia representaron el 84,2\% del total de las solicitudes en 2014, cifra que ha ido en aumento desde el 2005, lo que no es de extrañar, debido a que "Colombia, según los datos del Alto Comisionado de Naciones Unidas para los Refugiados (ACNUR) se encuentra entre los 20 países de origen con mayor número de solicitantes de refugio a nivel mundial" (DEM, 2016, p. 185).

\section{Inmigración en Chile y relación entre inmigración y refugio}

Chile se ha ido convirtiendo en los últimos años en un referente inmigratorio en Latinoamérica, recibiendo cada vez más poblaciones procedentes de diversos orígenes, con un notable aumento de población afrodescendiente, que llega en condiciones de gran vulnerabilidad (colombianos, dominicanos, haitianos). Sin embargo, como lo señalamos anteriormente, en cuanto a las solicitudes de refugio, la población colombiana es la más significativa porcentualmente. Además, es importante considerar que la migración colombiana hacia Chile se ha incrementado sostenidamente desde el año 2005, aumentando entre ese año y el 2014 en un 394\% (DEM, 2016, p. 151). Esto ha tenido efectos perversos en las representaciones y categorizaciones sobre los y las colombianos/as, asociadas a ser "negro" o "negra" (a pesar de que se sabe que no todos los y las colombianos/as son afrodescendientes y que no todos los y las afrodescendientes son colombianos/ as). Pero además, esta población se encuentra fuertemente asociada al narcotráfico, la delincuencia, la prostitución y la violencia en general (Amador, 2011; Valenzuela, 2009). Se trata de estereotipos de un grupo de connacionales que se convierten en estigmas, impulsados por un indignante sentimiento nacionalista de amplios sectores de la sociedad chilena, que han tomado a este grupo como el chivo expiatorio de las migraciones actuales. Tijoux expresa esta situación de la siguiente manera:
"La otredad opera como demanda de una corporalidad distinta que permite - una vez más- la constitución de un sí mismo chileno blanco y por lo tanto, diferente y separado de lo que lo constituye y que se debe excluir o separar. La diferencia marca al cuerpo Otro como una forma que deshumaniza, desposee de sentimientos y en ocasiones animaliza" (2014, p. 3). Ellas y ellos representan la alteridad absoluta en el Chile de hoy, son esa otredad excluida, que no merece ingresar al país, ni recibir ningún tipo de protección de sus derechos.

En cuanto a la migración forzada hacia Chile, ha sido estudiada por algunos autores principalmente en informes y algunas tesis (Valenzuela, 2009; Amador, 2011; Ramírez, 2011; Amstein, 2012; Becerra y Altamir, 2012; Bijit, 2012; Courtis, 2012), los que permiten hacer una caracterización acotada. En este sentido, podemos afirmar que son personas marcadas por múltiples situaciones de violencia, que no se organizan, ni se empoderan social ni políticamente en su condición de solicitantes de refugio, frente a sus propias problemáticas que viven dentro de la sociedad chilena (xenofobia, discriminación laboral, estigmatización en la prensa). Al contrario, solo se identifica la solicitud de apoyos asistencialistas, sin mayor incidencia en algún proyecto de vida en el país de acogida. Estos comportamientos son analizados desde una mirada crítica hacia las agencias del sistema humanitario; se trataría del resultado del paternalismo y del asistencialismo. Ramírez, en cuanto al ámbito laboral, imputa "que la colaboración está destinada a necesidades prácticas y a corto plazo, no capacitando o apoyando en dinero iniciativas microempresariales" (Ramírez, 2011, p. 139). Por su parte, Amstein afirma que ante la respuesta asistencialista, "no es inaudito que un porcentaje de refugiados desarrolle una postura y un estilo de vida caracterizado por encerrarse en la figura de la víctima" (Amstein, 2012, p. 161). Desarrollaremos este tema más adelante, puesto que en un inicio nos interesaremos en analizar las causas de la disminución de las concesiones de refugio en Iquique, situación que ha sido evidenciada por Courtis: "el notable descenso en la recepción de solicitudes de asilo [...] que parece reflejar no necesariamente una merma en la llegada de personas que desean solicitar asilo, sino que el surgimiento de dificultades para tramitar la petición ante las autoridades" (Courtis, 2012, p. 163). 
Es interesante expandir el lente para observar que a nivel internacional el número de refugiados sufrió de igual manera una disminución a partir del año 2000. Agier asocia este fenómeno al aumento de otras categorías, tales como el asilo territorial, asilo humanitario, etcétera, y señala: "al pasar de los años, la imagen dominante del exilio se transforma y toma sucesivamente la apariencia del refugiado, del desplazado interno, luego del solicitante de asilo rechazado, por tanto del clandestino" (Agier, 2006, p. 6, traducción libre). Así, vemos cómo un fenómeno global se repite a nivel local. En el contexto chileno, un factor que va a ser preponderante para el desplazamiento de categorías de personas extranjeras, es la Ley de Extranjería que extiende un velo sobre la nueva Ley de Refugio e impone la dificultad de lo que significa ser extranjero en Chile. La legislación vigente se basa en la doctrina de la seguridad nacional, propia del contexto político en el que fue promulgada: la dictadura militar, generando trabas ante los desafíos de la actual realidad migratoria. Bassa y Torres observan la caducidad de la legislación: "Este incremento progresivo en los flujos migratorios evidenciado en los últimos años tensiona la aplicación de un ordenamiento jurídico diseñado bajo la vigencia de un paradigma diferente del actual, insinuando su insuficiencia para enfrentar los desafíos de la nueva realidad social" (2015, p. 106).

El espíritu de esta ley, plasmado en las restricciones para el acceso, los permisos de estadía y las fuertes sanciones, implica que el extranjero es visto como una amenaza para la seguridad. Asimismo, Bassa y Torres plantean que la legislación de 1975 tensiona la garantía de igualdad ante la ley, que otorga la Constitución Política de Chile, ya que existirían restricciones al ejercicio de los derechos, diferenciadas de acuerdo al criterio nacionalidad (2015, p. 113). En todos los sectores se ha llegado a consensuar la necesidad de actualizar esta ley "anquilosada, restrictiva y lejos de las premisas de Derechos Humanos" (Stefoni, 2011, p. 81), pero entre los años 2013 y 2016 se generaron dos proyecto de ley en la materia que no han logrado entrar a discusión en el Parlamento.

En otras esferas de la sociedad podemos ver cómo se replica la problemática, por ejemplo cuando se plantea que los migrantes son una competencia la- boral que atenta contra la mano de obra nacional, o que ocupan "nuestros" servicios, en particular de salud (Liberona, 2012, 2015a). Estas tensiones se ven incrementadas por la creciente insatisfacción de la ciudadanía frente a problemas sociales no resueltos y por la tremenda desigualdad socioeconómica persistente en el país. Pero se trata de un problema de fondo que tiene que ver con la formación de la sociedad chilena, que se caracteriza por el no reconocimiento de su origen plural y mestizo, así como por la elaboración ideológica de una identidad chilena homogénea (Pavez, 2016; Subercaseaux, 2007), exacerbada por el nacionalismo colonizador de la post Guerra del Pacífico (S. González, 2004). Por tanto, un extranjero cuya apariencia física sea diferente al ideal "blanco europeo" es fácil presa de racismo (Liberona, 2015b), aún más cuando se trata de población "negra" asociada a servidumbre, a objeto de deseo, a una categoría inferior de ciudadano, consideraciones que son el legado del imaginario y la estructura colonial (Tijoux, 2014). Esto no es propio únicamente de la sociedad chilena; por lo mismo, nos interesa hacer una reflexión desde lo local, con el fin de contribuir al análisis del sistema humanitario internacional, y en este marco, consideramos pertinente no separar las categorías de refugiados e inmigrantes. Siguiendo esta lógica, Naranjo pone énfasis en los desafíos que significan estos procesos para la investigación social y política:

Las migraciones internacionales, puestas en el contexto de la globalización y de las transformaciones sociales, culturales y políticas transnacionales en el Sur global, configuran una tendencia a expresarse como migraciones forzadas, en un contexto que está produciendo patrones migratorios complejos y mezclados que requieren nuevas explicaciones desde las Ciencias Sociales y Políticas (2015, p. 267).

Buscando abordar estos desafíos, encontramos que los fenómenos se interrelacionan; es así como la literatura especializada ha demostrado que la migración forzada y la migración económica están estrechamente relacionadas; se habla del "nexo entre migración y asilo" (Castles, 2003). Naranjo destaca que "a menudo son indistinguibles y son formas de 
expresión de las desigualdades mundiales y las crisis sociales, que se han incrementado e intensificado desde la superación del orden mundial bipolar" (2015, p. 267). Es decir, que no podemos hoy en día tratar la problemática del refugio en Chile sin considerar estas relaciones. Es una evidencia que, tanto en el caso estudiado como en otros casos de estudio, los solicitantes de refugio no reconocidos, "rechazados" o "negados" -como se hacen llamar en Ecuador (Riańo, 2009, p. 62)- quedan al margen del sistema de protección humanitaria, a pesar de ser la expresión de los mismos conflictos y/o crisis sociales. Valenzuela afirma que "el conflicto armado ha contribuido al incremento de la migración”, principalmente porque la población civil busca huir de las zonas de combate y de las amenazas que reciben de los distintos grupos beligerantes, y también ha sido la principal víctima de la crisis económica y el desempleo generado por la violencia política (Valenzuela, 2009, p. 8). La sociedad civil colombiana que migra pasa a ser considerada "migrante"; poseen las mismas características que los refugiados, han vivido situaciones traumáticas y de carencias similares, pero no son reconocidos como tales. Desde el punto de vista de los derechos fundamentales, el cuestionamiento radica en que la migración forzada es experimentada por poblaciones cuyos derechos humanos han sido violados masivamente. Siguiendo a Gzesh (2008), la migración forzada puede también ser entendida como la consecuencia de la violación de los denominados DESC (derechos económicos, sociales y culturales) por parte de los Estados. Este enfoque plantea una extensión de los derechos, ya no solamente a la vida, a la seguridad, a la libertad, sino también al trabajo, a la salud, al agua, etcétera. En la misma línea, el ACNUR afirma que "los procesos fallidos y errados de desarrollo contribuyen a las causas generadoras de migración forzada" (2007, p. 3). Por lo tanto, el problema radica en que las causas para solicitar refugio sobrepasan lo acordado en la Declaración de Cartagena ya que, de acuerdo a $\mathrm{Na}$ ranjo, "en la mayoría de los casos, la población no huye de una persecución individualizada" (2015, p. 271); las causas están más relacionadas a "poderosas sensaciones de injusticia y miedo que, a su vez, producen sentimientos profundamente arraigados de persecución, lo cual lleva a las personas a reclamar la etiqueta de refugiados" (Naranjo, 2015, p. 270).

\section{Disminución de las concesiones de refugio en Iquique}

A continuación pasaremos a revisar el caso de estudio, partiendo por el análisis de la información oficial. En la Tabla 1 se evidencia el alto número de solicitantes de refugio en los primeros años de instalación de las oficinas ${ }^{10}$ del Programa Refugio Iquique, 2008-2009, sin que aún se promulgara la Ley de Refugio. Posteriormente, se observó una baja considerable de solicitudes y de reconocimientos, llegando a contar en 2012 solamente con tres casos (Tabla 2) acogidos por el programa, que compartían la siguiente característica: ingreso regular gracias a la documentación que justificaba la condición (actas de defunción, denuncia de la presunta desgracia). La tendencia fue similar en los años posteriores, ${ }^{11}$ con un leve aumento en los últimos ańos: cinco casos en 2013; seis entre mayo y diciembre de 2014 (período en que se llevó a cabo el programa de Refugio, los otros meses no se dio atención); 15 casos en 2015 y 11 en abril de 2016.

Esta disminución sostenida de casos acompañados por el Programa de Refugio, así como de solicitudes reconocidas, se debe en gran medida a las dificultades en el procedimiento para acceder a la preadmisibilidad. Uno de los problemas identificados en la zona norte, en particular en Iquique, reside en la dificultad de la población solicitante de refugio de origen colombiano de conocer los procedimientos normativos que indica la actual Ley de Refugio, que establece ciertos plazos para la tramitación. Pero otro problema relevante que se ha identificado a través de la participación en el Programa Refugio es que la aplicación de esta Ley en las gobernaciones provinciales fronterizas -como la de Iquique- está sujeta al tipo de ingreso al territorio nacional. Los relatos de las personas atendidas en el Programa Refugio señalan que al solicitar asilo en la frontera,

10 Es importante indicar que en Iquique desde el año 2007, después de un proceso de evaluación se estableció a un grupo de aproximadamente 30 personas en condición de reasentamiento en la zona norte del país.

11 Estos datos fueron entregados por la actual encargada del programa, en una entrevista realizada el 6 de abril de 2016. Ella señala que el ingreso irregular sigue siendo el motivo de inadmisibilidad al proceso de solicitud. 
Tabla 1. Solicitudes de refugio entre 2006 y 2010. Gobernación de Iquique.

\begin{tabular}{|c|c|c|c|c|c|c|}
\hline \multirow{2}{*}{$\begin{array}{c}\text { Ańo } \\
\text { Solicitud }\end{array}$} & \multicolumn{2}{|c|}{ Solicitudes de refugio } & \multicolumn{2}{c|}{ Reconocidos } & \multicolumn{2}{c|}{ Rechazados } \\
\cline { 2 - 7 } & Femenino & Masculino & Femenino & Masculino & Femenino & Masculino \\
\hline 2006 & 216 & 325 & 68 & 106 & 148 & 216 \\
\hline 2007 & 323 & 372 & 57 & 40 & 263 & 328 \\
\hline 2008 & 396 & 462 & 50 & 54 & 166 & 188 \\
\hline 2009 & 251 & 274 & 32 & 32 & 41 & 59 \\
\hline 2010 & 93 & 127 & 4 & 5 & $\mathbf{9 4 6}$ & $\mathbf{1 1 7 8}$ \\
\hline Totales & $\mathbf{1 2 7 9}$ & $\mathbf{1 5 6 0}$ & $\mathbf{2 1 1}$ & $\mathbf{2 3 7}$ & & \\
\hline
\end{tabular}

Tabla 2. Número de casos de acompañamiento por el Programa Refugio.

\begin{tabular}{|c|c|c|c|}
\hline \multirow{2}{*}{ Ańo } & \multicolumn{2}{|c|}{ Género } & \multirow{2}{*}{ Universo } \\
\cline { 2 - 4 } & Masculino & Femenino & 110 \\
\hline 2008 & 52 & 58 & 113 \\
\hline 2009 & 5 & 62 & 15 \\
\hline 2010 & 4 & 3 & 7 \\
\hline 2011 & 2 & 1 & 3 \\
\hline 2012 & $\mathbf{1 1 3}$ & $\mathbf{1 3 4}$ & $\mathbf{1 4 6}$ \\
\hline Total & 51 & 34 \\
\hline
\end{tabular}

*Información del Programa Refugio Obispado Iquique 2012.

se encuentran con juicios arbitrarios por parte de funcionarios de la Policía de Investigaciones (PDI), que en algunos casos niegan injustificadamente el ingreso a Chile. Por tanto, no encuentran otra opción que ingresar clandestinamente. Sin embargo, el ingreso irregular es la principal fundamentación de la inadmisibilidad al debido proceso. ${ }^{12}$ He aquí un problema que responde al mismo tiempo a una cultura institucional de la PDI y al desconocimiento de la Ley de Refugio. Los funcionarios que realizan el control migratorio en la frontera, siguiendo el

12 Las consecuencias de este tipo de ingreso son reconocidas como "riesgos para la seguridad personal no solo porque se trata de una zona inhóspita, sino también porque allí operan redes de tráfico y de trata humana” (Courtis, 2012, p. 172). Asimismo, Amador describe: "En los relatos de las mujeres hay testimonios de maltrato, engaño y violencia por parte de estos traficantes, quienes juegan con la vida y esperanzas de estas personas" (Amador, 2011, p. 96). espíritu y la potestad que les otorga la Ley de Extranjería, aplican un criterio discrecional en función de la persona que solicita el ingreso al país. Esto ha sido estudiado desde el punto de vista jurídico, entre otros, por Bassa y Torres quienes manifiestan que:

La regulación normativa vigente da paso a una eventual afectación del derecho a la igualdad ante la ley, en atención al amplio margen de discrecionalidad que el art. 13 inc. $1^{\circ}$ del D.L. No 1.094 le entrega a la autoridad administrativa [...] sucede con las causales legales de expulsión y prohibición de ingreso [...] al fundamentar las sanciones en la protección de bienes jurídicos relevantes para el Estado, tales como la seguridad nacional, el orden público o la seguridad pública, entre otros, pero en ausencia de criterios 
legales que permitan orientar la ponderación o proporcionalidad en la determinación y aplicación de dichas medidas (2015, p. 114).

La denegación del ingreso, ya sea por desconocimiento, por falta de criterio o por arbitrariedad, ha sido aplicada indistintamente a solicitantes de refugio y opera como "una suerte de círculo vicioso" (Courtis, 2012, p. 172). En estos casos, los y las solicitantes se encuentran "rebotados/as" en la frontera, pero esto no impide su ingreso al país. Sin embargo, una vez que solicitan el asilo, el ingreso irregular les impide acceder al debido proceso. Las personas son, en su mayoría, derivadas a la PDI, sujetas a control de identidad y posteriormente, según resolución de la Intendencia Regional, se ordena su expulsión del país. Este procedimiento se desprende de una instrucción proveniente del nivel central, que se ajusta a una interpretación de la ley por parte de las autoridades locales. ${ }^{13}$

La principal consecuencia es que muchos solicitantes rechazados o con orden de expulsión optan por quedarse en el país de forma clandestina. Esto se traduce en una situación de gran vulnerabilidad, en primer lugar, debido a la falta de documentación, a lo que se suma la baja escolaridad, que dificulta la empleabilidad. Una particular atención requiere la situación de las mujeres afrocolombianas, quienes se ven más afectadas por situaciones de explotación laboral y sexual e incluso trata de personas, según

13 "Suscitan también preocupación una serie de prácticas ejercidas por los funcionarios de Extranjería en las gobernaciones provinciales encargados de recepcionar las solicitudes de asilo, que apuntarían a evaluar si la petición responde a las causales de inclusión propias de la definición de refugiado adoptada en la Ley de Protección a Refugiados o a otros móviles, de modo de acoger o no el trámite $-\mathrm{y}$, en este último caso, brindar orientación sobre otras visas-. Dichas prácticas constituirían una instancia previa al procedimiento de determinación del estatuto de refugiado/a - de allí que se hable de pre-admisibilidad-, que obstaculiza/impide el acceso a dicho procedimiento en forma incompatible con el principio de no devolución de la Convención de 1951 sobre el Estatuto de los Refugiados y con el propio texto de la Ley No 20.430, donde se establece que la función de decidir sobre el reconocimiento o rechazo de las solicitudes de asilo recae única y exclusivamente en el Subsecretario del Interior" (Courtis, 2012, p. 173). la información proporcionada por las funcionarias del programa, algo que también constata en su investigación Amador (2011). En segundo lugar, esta población tiende a ocultarse de la policía (PDI), ya que al ser interceptados, son trasladados a los cuarteles para el control de identidad y quedan sujetos a firma, en espera de que emane la orden de expulsión de la Intendencia. Esta situación ha provocado una invisibilidad de la población de interés de ACNUR, que desconoce su magnitud. Dicha población se ha movido a otras ciudades (Antofagasta) y/o ha escogido otro tipo de visa, alejándose de las redes de protección que el programa les brinda en la zona.

\section{Acogida, solicitud de asilo y experiencia en Iquique}

Iquique es una ciudad ubicada en el desierto costero del norte de Chile, correspondiente a la región de Tarapacá, la cual comparte frontera con Bolivia. Históricamente y también en la actualidad, la ciudad surge y crece principalmente gracias a la minería, presentando un atractivo para la fuerza laboral, conformándose como sociedad de acogida de la migración interna e internacional. En este contexto se incorporan los solicitantes de refugio.

De manera general, la población solicitante de refugio en Iquique está compuesta por jóvenes de ambos sexos, de un rango etario entre 18 y 45 ańos, aunque se dan algunas excepciones de personas mayores, de alrededor de 60 años, o de niños/as de 1 a 10 años. Se registra un mayor número de mujeres solas que dejan a sus hijos/as al cuidado de familiares y luego de un tiempo solicitan reunificación familiar, por lo que al cabo de un tiempo se trata de mujeres con sus hijos/as. Esta población presenta un bajo nivel de instrucción educacional, generalmente su formación es incompleta y tienen pocas calificaciones técnicas, incluso es posible encontrar a algunas personas analfabetas. El lugar de origen de esta población es principalmente Colombia y en particular de la zona denominada "Costa Pacífico": Buenaventura, Nariño, etcétera, ${ }^{14}$ donde gran parte de ella se reconoce como afrodescendiente. Se caracterizan también por no tener experiencia laboral, por tanto

14 Denominadas por el ACNUR como "zonas rojas", sitios de guerrilla y narcotráfico. 
las personas consiguen trabajo de manera informal, generalmente asociado a la labor doméstica.

Las condiciones estructurales que justifican la condición de refugio son el impacto y/o vinculación directa e indirecta con la guerrilla o con los paramilitares. En este sentido, hemos constatado que en la ciudad se generan situaciones de encuentro entre victimarios y víctimas. Otra de las condicionantes es el desplazamiento interno o la migración forzada de personas de limitadas condiciones económicas que han optado por venir a Chile en busca de mejores oportunidades laborales. Asimismo, se extiende al desplazamiento desde países limítrofes de Colombia tales como Ecuador, Perú o Venezuela, hacia Chile.

En este contexto se instala el Programa Refugio en Iquique el año 2007, y se debe a dos principales motivos: la ciudad había sido escogida como lugar para situar a un grupo de familias reasentadas; y debido al aumento de solicitantes de asilo en las zonas fronterizas, como la región de Tarapacá. Hasta antes de 2007, las personas debían solicitar refugio en la capital de Chile, Santiago, pero, ante el aumento de población de interés para el Alto Comisionado de las Naciones Unidas para los Refugiados (ACNUR) en la zona, la Vicaría Pastoral Social y de los Trabajadores (agencia implementadora dependiente de FASIC ${ }^{15}$ ) establece un trabajo administrado desde Santiago en Iquique. Así, se traspasó el programa al Obispado de Iquique, el cual el año 2010 se independiza de la Vicaría Pastoral Social y de los Trabajadores, lo que significó una reducción de recursos y personal. En un inicio el trabajo de la institución estaba principalmente dirigido a hacer seguimiento a las familias reasentadas en Iquique, para dedicarse posteriormente a la orientación y acompańamiento de solicitantes de asilo y refugiados, residentes en

15 La Fundación de Ayuda Social de las Iglesias Cristianas (FASIC) fue fundada el 1 de abril de 1975, como continuadora del trabajo iniciado por el CONAR (Comité Nacional de Ayuda a Refugiados) en septiembre del año 1973. Es una institución de carácter ecuménico, comprometida con la práctica cotidiana de los derechos humanos e inspirada en la perspectiva cristiana de liberación y dignidad de las personas. Se planteó su misión en una concepción ecuménica amplia, en la que participan no solo miembros de diferentes Iglesias, sino también personas que expresan distintas opciones religiosas. las ciudades y localidades de la región de Tarapacá. Además de fortalecer las redes de apoyo con las instituciones públicas y privadas, y hacer cumplir lo establecido en la Ley 20.430, conocida como Ley de Refugio del ańo 2010.

\section{Resultados de la participación en el programa y del Diagnóstico Participativo}

A continuación se describe el funcionamiento del programa y se presenta la información que las funcionarias del mismo han levantado, ${ }^{16}$ incorporando extractos del Diagnóstico Participativo.

El Programa Refugio se enfoca en casos individuales o familiares. Las principales consultas conciernen la orientación para trámites administrativos en los diversos servicios públicos, en particular los procesos de postulación a vivienda. La atención está direccionada hacia cuatro categorías, según lo establece el ACNUR, dependiendo de la población de interés:

- Solicitantes de refugio

- Refugiados reconocidos por el Gobierno de Chile

- Refugiados reasentados (aquellas personas que fueron solicitantes de refugio en un país, en el que no sintieron que se les brindara la protección necesaria y solicitaron al ACNUR que los envíe a un tercer país)

- Personas no admitidas al debido proceso y solicitantes rechazados

El programa adicionalmente acompaña y asiste económicamente, ${ }^{17}$ según un convenio entre el Departamento de Acción Social del Ministerio del Interior y Seguridad Pública del Gobierno de Chile. Mantiene contacto con FASIC de Arica, Antofagasta y Calama, como red de apoyo a los casos que se trasladan de ciudad. Según sus funcionarias, el programa despliega una orientación integradora capaz

16 Redacción basada en la sistematización de la práctica profesional, así como en dos entrevistas en profundidad a funcionarias del programa, una en 2015 y la otra en 2016.

17 Esto implica el pago de un arriendo los primeros meses de instalación y el pago de trámites. Cubre además la alimentación, el transporte, enseres básicos para el hogar y ayuda económica para estudios. 
de responder a las necesidades humanitarias inmediatas de todo aquel migrante forzado que solicita protección internacional en Chile, de acuerdo a los protocolos diseńados por el ACNUR, los cuales son adaptados al contexto local. Se busca la protección, resguardo y promoción de los derechos fundamentales con enfoques diferenciados. El Programa de Refugio vela por el respeto a las decisiones asumidas como individuos y/o familias.

\section{1) Ingreso a Chile y evaluación del programa}

La intervención social que se lleva a cabo se hace de forma individual, primeramente mediante una entrevista en privacidad. Pese a ello, muchos de los y las solicitantes no quieren identificarse, por el terror de seguir siendo perseguidos o expulsados, no confían en nadie. Las funciones del/de la trabajador/a social generalmente consisten en entregar orientación y permitirles hablar, desahogarse, ya que posteriormente necesitan exponer su problema frente a las autoridades, quienes toman la decisión de reconocimiento de la condición de refugiado o no. Generalmente estas personas vienen cargadas de dolor, impotencia, a lo que se suma la mala acogida desde su llegada a Chile. Así lo manifiestan las solicitantes de asilo, quienes se sienten atemorizadas frente a los agentes de la PDI:

Traía los documentos para solicitar refugio... $y$ asi lo hice, le informé al oficial... un tipo muy duro ;Ayyy, berraco!... Tuve que soportar unas horas de pie antes de poder apostillar el pasaporte. Observaba que entre ellos hablaban sobre mis documentos. Son muy vulgares para tratar en la frontera, no respetan nada... pero hasta que por fin entré... (Luz María, 48 años).

Se explica el procedimiento para la solicitud de asilo, que les permite regular su residencia en el país, ya que generalmente llegan sin tener ningún conocimiento. En línea con este testimonio, Courtis manifiesta que existe desconocimiento y temor al rechazo, lo que traería como consecuencia que "las personas que solicitan asilo en la frontera son menos de las que podrían hacerlo". Asimismo se cuestiona "la ausencia de una actitud proactiva" de la PDI, "en la identificación de posibles solicitantes de asilo y la provisión de información pertinente" (Courtis, 2012, p. 172). Cabe destacar que durante el tiempo que se llevó a cabo la práctica profesional, se rechazaron cerca de 30 casos en un proceso llamado de "pre-admisibilidad", de los cuales muchos tenían razones justificadas (documentos) para entrar en la categoría de "solicitante de asilo". Se detectó que si los y las solicitantes manifestaban su intención de trabajar, inmediatamente se los catalogaba como "migrantes económicos" y la solicitud era considerada inadmisibles al debido proceso. Por tanto, una de las medidas tomadas dentro del programa fue enseñarles a no pronunciar la palabra "trabajo" en la entrevista de pre-admisibilidad.

En el Diagnóstico Participativo, las opiniones en cuanto a estas entrevistas son más bien positivas. En general, las mujeres mencionan el trato respetuoso de la funcionaria a cargo, a pesar de manifestar que se trata de una experiencia "difícil".

Para mi si que fue más difícil, yo entré ilegal
y se me hacia más difícil, esto fue febrero...
cuando fui donde la señora Eugenia, ella muy
correcta lo primero que me dijo fue enviarme
a la PDI a autodenunciarme... Allá me qui-
taron los documentos y luego me entregaron un
documento que decía "Extranjero Infractor", y
volvi a la Gobernación, ahora sí a la entrevis-
ta, me citaron para darme una respuesta días
después... (Betty, 36 años).

El programa también realiza charlas informativas; se trata de una instancia grupal para entregar información en profundidad sobre diversos aspectos o dimensiones de la vida en Iquique, con la participación de instituciones tales como Salud, Inspección del Trabajo, Oficina Provincial de Educación, DEM, entre otras. Se lleva a cabo luego una segunda entrevista personal, que tiene por objeto discutir con mayor profundidad los aspectos abordados en la entrevista inicial y comenzar a dar forma a un plan de trabajo para los primeros dos o tres meses.

Con respecto a la información entregada en el Programa Refugio y en el DEM, sección Refugio, la evaluación es positiva, a pesar de que este último 
solo atiende ciertos días de la semana a la población que solicita refugio, agregando burocracia a los trámites y largas esperas. Pero se consignan problemas en cuanto a hacer valer los derechos de esta población a nivel intersectorial y cuando se tiene que operar con las redes a las cuales se deben derivar los y las solicitantes de refugio:

Acá me han dado la orientación muy clara y yo he seguido sus órdenes, solo que en el consultorio tuve problemas con la inscripción... o ¿cómo se llama?.. cotizaciones, eso, previsional y cédula... y le dije que era refugiada, que eso estaba en trámite... pero la funcionaria no sabía qué era eso (Yovanna, 27 años).

Quienes solicitan asilo y son reconocidos como tales, según la Ley 20.430, están autorizados a residir en Chile con una visa de residencia de ocho meses, mientras es evaluada y se investiga su aceptación a la condición plena de refugiado o su rechazo.

\section{2) Proceso de inserción a nivel local y/o nacional y las condiciones estructurales y contextuales del mismo: vivienda, educación, salud y trabajo}

Las personas que solicitan asilo llegan solas, pero con algunas redes de apoyo familiar (primo/a, tío/a, sobrino/a), que ya están radicando en Iquique como refugiadas $y / 0$ inmigrantes. Muchos han pasado la frontera de Chile de forma irregular, mayoritariamente por Bolivia (Colchane) pero también por Chacalluta, con ayuda de redes de tráfico. Pagan a "coyotes" cifras que van desde unos 100 dólares por persona, ${ }^{18}$ ocultando los documentos claves como el pasaporte y pasado judicial. Antes, han tenido que pagar en el cruce de otras fronteras, entre Colombia/ Ecuador, Ecuador/Perú, Perú/Bolivia, en escalas diversas de cobros que podrían sumar hasta 500 o mil dólares de gastos.

Se insertan territorialmente en el casco viejo de Iquique (sector mercado, barrio boliviano) en condiciones de habitabilidad precarias y de gran hacinamiento:

18 Amador (2011) afirma que serían 200 dólares por persona para ingresar a Chile.
Yo llegué a la pieza donde vive mi mamá, ella tiene mucho tiempo viviendo alli, pero ella quiere buscar otro lado, pero el arriendo para los colombianos es más caro que para los otros... tengo una amiga peruana que le cobran 60 mil y mi mamá paga 130 mil por una pieza un poco más grandecita, además eso de que tenemos un día para lavar es verdad, que tenemos que ocupar poca luz y agua, no se puede hacer nada, si no nos echan. Estamos sometidos a lo que el dueño dice. El baño, son dos para 27 personas, y siempre está sucio... Yo no sé cómo no me enfermo (Vanessa, 17 años).

En general, se trata de una pieza de material ligero, de un costo elevado, ubicada en casas en las que se han construido o subdividido espacios para tener muchas piezas en alquiler, donde se producen fuertes tensiones con personas nacionales y de otros grupos de inmigrantes, debido a las dificultades propias de las precarias condiciones de habitabilidad. Esto ha sido consignado igualmente por otros autores como Valenzuela (2009) Amador (2011) y Contreras, Ala-Louko y Labbé (2015). El siguiente relato nos ayudará a describir la dificultad que tienen los y las colombianos/as de ser aceptados/as como arrendatarios/as:

Cuando llegué aqui, Raúl estaba en una pie$z a$ donde los cuatro dormíamos en la misma cama, pero mi hija necesitaba un lugar donde dormir solita, ella es una señorita y eso me llevó a buscar otro lugar, habian varios lugares donde volteé para consultar pero cuando me escuchaban hablar me decian: "A colombianos, no! yo a colombianos no les arriendo, porque son de mal vivir...". Y asi perdi sin exagerar como 10 lugares, he recorrido muchos lugares, he conocido todo Iquique (Luz Rubi, 33 años).

Durante la práctica profesional, se observaron un sinnúmero de situaciones en las que destaca el incumplimiento de lo establecido en la Ley 20.430 relativa a los y las solicitantes de refugio y refugiados/ as. En particular, en el área de Educación; la mayoría de la población solicitante de refugio no trae consigo los documentos escolares de sus hijos/as ni los timbres del consulado chileno que los validen. 
Esto perjudica el acceso a la educación de niños y niñas, que en muchos casos no entran al sistema escolar, vulnerándose el derecho a la educación. En este tema las participantes del grupo de discusión manifiestan nudos críticos más complejos. Principalmente, se identifica burocracia en la atención para la obtención de la matrícula y discriminación por parte de los directores de los establecimientos, que niegan arbitrariamente las matrículas.

\section{Yo si que aqui he tenido problemas, me dirigi a la escuela Centenario, quedaba a una cua- dra de la casa donde vivia, pero cuando llegué alli, le pregunté al señor de la puerta y me dijo que hablara con el director, entré a su oficina $y$ sin terminar de explicar me dijo que no tenía matrícula, le comenté que yo era refugiada, y al parecer el señor no sabe qué es eso, porque me dijo que él tenía muchos extranjeros en su colegio y que no quería más porque después no los puede cursar a otro nivel porque no traen los documentos. Yo traje los documentos de Mi- chel, pero a él no le importó, simplemente me dijo que no, volteé por varios colegios y no hubo resultado... (Luz Rubi, 33 años).}

Se observa que los y las niños/as sufren durante su adaptación al sistema escolar, debido a los hostigamientos por parte de la comunidad local, que se manifiestan en actos de agresión, los que identifican como bullying.

\section{¡Ay Dios! Aqui si que tengo que decir algo malo, porque a mis niños si les han hecho eso que... ¿Cómo se llama? Maltrato en la escue- la... Ab! Eso, bullying... Le gritan a Maykol: "Se oscureció, oye negro culiao, carbón"... No, eso es penoso, cómo le dices a un niño que eso no se hace, si no le obedecen a los profesores, qué me van a hacer caso a mi... a Jenny lo mismo, solo que Jenny es más berraca y responde, ya le ha pegado a un niño... por decirle negra he- dionda... En los colegios no saben qué es ser refugiado (María, 59 años).}

Esta violencia se suma a situaciones discriminatorias en los Centros de Salud Primaria, donde muchas veces no se brinda la atención al solicitante de refu- gio si éste no cuenta con cédula de identidad que lo acredite como refugiado. Sin embargo, al estar inscritas en la atención primaria, las solicitantes de refugio declaran que reciben una buena atención: " $Y o$ he llevado a Keytti a controles y me entregaron leche y hora para médico, no he tenido ningún problema" (Yuranni, 28 ańos).

A veces, se quejan de algunas situaciones incómodas para ellas, que dan cuenta de la incapacidad de algunos/as funcionarios/as de ponerse en el lugar del otro, como el siguiente testimonio:

Para mi... ustedes ven, yo soy una mujer vieja... [risas] y me dice la muchacha que me tomó la muestra, si yo tenía actividad sexual... Yo no he tenido hombre desde hace ya casi 20 años, eso lo considero una insolencia... ;Cómo me pregunta eso, si yo soy ya abuela... iQué actividad sexual! ;No venga... [risas] atrevida! (María, 59 años).

Laboralmente no tienen posibilidad de insertarse con éxito, puesto que no se reconocen sus derechos laborales. Al igual que todos los migrantes de la ciudad, tienen los trabajos más duros o de segunda categoría, padecen situaciones de explotación y precariedad laboral, con largas jornadas y malas condiciones de trabajo. Son empujados a trabajar informalmente en la construcción, o como cargadores de la Zona Franca de Iquique (ZOFRI), en labores de aseo o en oficios como la venta callejera de comida, meseras en shoperías para ganar por día cinco mil pesos chilenos (equivalentes a 7,2 dólares aprox.). Otras actividades, como la prostitución o actividades callejeras ilícitas (asaltos, microtráfico de drogas), les permiten capitalizar no menos de 400 mil pesos chilenos mensuales (equivalentes a 580 dólares aprox.), generando en algunos casos dependencia de redes mafiosas. ${ }^{19}$

19 Amador afirma que la prostitución termina siendo una estrecha salida para la situación de las mujeres afrocolombianas, quienes no tendrían oportunidades en el trabajo doméstico: "El costo de vida en Chile es 4 veces más alto que en Colombia, por lo que la plata que llevaban las mujeres se acaba rápido, situación que sumada a la discriminación racial, la indocumentación y la sexualización de su raza crea el escenario perfecto para caer en grupos de explotación sexual o ejercer la prostitución 
De las participantes en el diagnóstico, tres declaran que están trabajando de manera informal, debido a que los empleadores no le dan importancia al contrato; ellas no insisten por temor a perder el trabajo.

Yo estoy trabajando hace un mes en un hotel, de mucama y no tengo contrato, porque al jefe siempre que le hablo del tema me dice que después... Sí, pero me da miedo, necesito trabajary me ha costado encontrar trabajo. A nosotros nos cuesta encontrar trabajo (Yovanna, 27 años).

Por otro lado, las condiciones laborales no se ajustan a lo que la ley establece, ya que deben pagar ellas mismas sus imposiciones y les descuentan las horas cuando deben realizar algún trámite relacionado al procedimiento para obtener la condición de refugiadas.

A ver, en mi trabajo las cosas no son buenas... me hacen trabajar más de ocho horas y no me dan permiso para hacer algún trámite cuando debo ir a la Gobernación, por el contrario me hacen pagar los permisos, me dicen que soy un problema para la empresa, y me descuentan las horas o a veces el dia... Todo... Son abusadores" (Luz María, 48 años).

No recurren a la Inspección del Trabajo porque no cuentan con contrato y en muchos casos se encuentran sin documentos. Pero además, según la experiencia del Programa Refugio, en la Inspección del Trabajo no se toman en cuenta las denuncias que realizan extranjeros. Bijit, al analizar los procesos de integración social de los refugiados palestinos en Chile, destaca que un aspecto que influye en ésta "es la diferencia existente entre las condiciones de trabajo del mercado laboral de origen y el de destino" (Bijit Abde, 2012, p. 169). Sin embargo, en el caso estudiado, las condiciones de vida en origen son de gran pobreza y de innumerables restricciones. A pesar de esto, las mujeres señalan la dificultad de encontrar trabajo, los abusos por parte de los empleadores y la falta de documentación como factor de riesgo y de precarización de sus vidas. La precariedad laboral es sin duda determinante; Bijit sostiene que guarda relación con el problema que

para sobrevivir" (Amador, 2011, p. 97). se encuentra tras la integración social de los refugiados palestinos en Chile, identificando como una consecuencia "el acceso a servicios básicos estratificados en función del ingreso" (Bijit Abde, 2012, p. 178). Asimismo, otro factor determinante en la inestabilidad e inconstancia laboral de los refugiados es, según Courtis, "la extenuante burocracia chilena que resulta ser muy compleja e impone una serie de dificultades a las cuales no estaban para nada habituados los sujetos" (Courtis, 2012, p. 162).

\section{3) Integración a la sociedad chilena, discriminación y seguridad}

Uno de los asuntos más delicados a tratar con esta población es el de la integración, ya que inmediatamente surge el tema de la discriminación. Nos referimos a la integración social como fenómeno "afectado por múltiples factores" que, siguiendo a Bijit (2012, p. 161), es posible analizar a partir de enfoques que reconocen "la complejidad y multidimensionalidad del fenómeno", identificando factores externos (marco jurídico, mercado laboral, condiciones políticas y actitud de la sociedad de acogida) y factores internos (cualificación profesional, disposición de los sujetos a interactuar con su entorno social, construcción de redes de solidaridad, aprendizaje del idioma y mejoras en sus condiciones de vida) a los inmigrantes (Bijit Abde, 2012). En el caso estudiado, observamos la ausencia de integración social y la preocupación de las mujeres especialmente por sus hijos e hijas, reconociendo que la discriminación es una constante y que afecta de manera profunda la convivencia y la integración a la sociedad chilena.

Michelle en la escuela tiene compañeritos chilenos que la han recibido bastante bien, pero las niñas no, ellas la empujan, la pasan a llevar. Los profesores en los colegio les dicen a los niños que estorban... Aun asi yo estoy tranquila por mi y mis hijos (Luz Rubi, 33 años).

A mi me han gritado "Mono, queris mani", y no me paran los colectivos... yo me siento mal, me dan ganas de gritarles cosas pero me da pena... no tengo amigos chilenos, sí colombianos. Ellos son mis buenos amigos... (Vanessa, 17 años). 
Más que discriminación, consideramos que se trata de exclusión y de racismo, y quienes más lo sufren son las mujeres afrodescendientes:

\section{Ha sido lo más difícil de todo, cada vez que voy caminando por las calles de Iquique, no falta el irrespetuoso que me lanza garabatos... me dicen: "Negra culiá... maraca... ¿Cuánto cobrai?". Son los colectiveros. Un día un auto se detuvo y yo me acerqué pensando que me preguntaría algo y me dice: "Súbete, la vamos a pasar bien". Yo ya soy una mujer mayor. No creo que me merezca un trato asi (Luz María, 48 años).}

Las representaciones sociales sobre la inmigración "negra" generan una violencia simbólica y verbal que se relacionan con la exclusión y con el maltrato directamente: "Hay señoras que se corren cuando pasan por mi lado. No me quieren arrendar por ser negra, no me dan trabajo por ser negra... Qué pecado, ¿eh?" (Betty, 36 años).

Asimismo, aparece el sentimiento de seguridad, lo que marca la diferencia para estas mujeres que escapan de otro tipo de violencia: "Acá uno puede caminar por las calles y no tiene temor de las bombas. Voy a la playa sin miedo" (Luz María, 48 años). "Acá me siento de verdad muy tranquila, duermo tranquila. Mi hijo sale al internet y no tengo miedo de que lo vayan a matar" (Betty, 36 ańos).

Para comprender estas palabras, es necesario dar cuenta del contexto de origen que, tal como lo mencionamos anteriormente, está inmerso en una situación de conflicto generalizado. Ramírez en su tesis sobre los refugiados colombianos en Chile presenta el cuadro de contexto como una "guerra interna" citando a Zuluaga, para quien "la guerra interna 'es un síntoma de la carencia de una institucionalidad democrática' (Zuluaga, 2001, p. 3), destacando la inequidad existente como producto de la injusticia social, motivando la rebeldía de grupos insurgentes, que a partir de 'la consolidación del narcotráfico, el derrumbe catastrófico del llamado campo socialista que puso fin a la Guerra Fría y la expansión del fenómeno paramilitar' (Zuluaga, 2001, p. 3) se hicieron propicio espacio" (Ramírez, 2011, p. 47).
Esta situación de conflicto va a expresarse incluso en lo que concierne a las relaciones personales de los y las solicitantes de asilo o refugiados/as colombianos/ as. Nuestra participación en el programa nos permitió observar que es común que constituyan nuevas relaciones sentimentales y familiares de hecho. Estas nuevas relaciones implican un crecimiento de la población, por tratarse de un segmento joven sin mayores controles de fertilidad, ya sea por la falta de acceso a los chequeos en los servicios médicos públicos o por no tener una cultura de prevención y cuidado en su salud sexual y reproductiva. De lo anterior se desprende que comienzan a nacer niños y niñas en un ambiente de marginalidad, lo que los hace vulnerables en su desarrollo. También se han manifestado relaciones interpersonales en tensión, con no pocas violencias intrafamiliares, psicológicas y físicas para el grupo familiar de hecho. Courtis, al describir el trabajo de las agencias del sistema humanitario en Chile, identifica la violencia familiar como una preocupación de quienes trabajan con la población refugiada (Courtis, 2012). En este sentido, aparece una vez más la importancia de considerar el contexto de origen. Becerra y Altamir, analizando el refugio palestino, explican que para comprender estas manifestaciones de violencia, es importante incorporar a la reflexión y al diagnóstico terapéutico el contexto del refugio:

[L]a violencia va impregnando a padres, hijos y las relaciones que establecen entre ellos y con los otros. Es así como la guerra, la persecución política, la desconfianza, el miedo, la inseguridad, van dejando huellas profundas, cuyas secuelas pueden expresarse en nuestro país, aun cuando la persona se encuentre ya en relativa seguridad (Becerra y Altimir, 2012, p. 207).

Pero para incorporar el origen, es necesario cuestionar nuestros marcos teóricos y conceptuales. A modo de ejemplo, y a propósito de los refugiados palestinos en Chile, Amstein recurre al concepto de habitus para "entender varias de las lógicas comprendidas en las pautas de comportamiento [...] así como los roces y las controversias que se suscitaron al tener que moldearse a situaciones contrarias a sus propios habitus, generando de esta forma más de 
una reluctancia por parte de éstos" (Amstein, 2012, p. 109). De esta manera, el autor -interpretando lo expresado por los refugiados, como por los integrantes del equipo de refugio- atribuye al habitus de los refugiados "los principales problemas que se interpusieron en el camino" (Amstein, 2012, p. 160), refiriéndose a los procesos de integración. A pesar de tratarse de grupos muy distintos de refugiados, es interesante el análisis ya que el autor hace responsables a los refugiados de los problemas que las instituciones no habían previsto que podían suscitarse. Nuestra pregunta, en el caso del refugio colombiano, es ¿qué pasaría si usamos el habitus como marco conceptual? Pues bien, estaríamos contribuyendo a la construcción social de la diferencia y a la exclusión de los y las colombianos/as.

Los procesos de exclusión y racismo que han sido atribuidos por Amador (2011) a la hipersexualización de la "raza negra" se suman a la deslegitimación de la condición de refugiado, identificado por Ramírez en las dificultades que tienen las y los colombianos para buscar empleo. "El proceso de asilo tiene desventajas en materia de legitimación social de documentación de trabajo" (Ramírez, 2011, p. 136).

Vimos a lo largo de este apartado que en todas las dimensiones consideradas en este estudio de caso aparecen situaciones que implican la negación de los derechos humanos, en un sentido amplio: derecho a la vivienda, derecho al trabajo, derecho a la educación, lo que nosotras interpretamos como violencia institucional. Tomando el caso de los palestinos, Becerra y Altamir hacen un análisis de las condiciones de salud mental de niños, niñas y adolescentes refugiados y plantean que "[l]a entramada situación de precariedad genera contextos que exponen a las familias a diversas formas de abuso y de violencia, implícita y explícita”. Las autoras explican que "la discriminación y la dificultad en el acceso a servicios pueden ser vivenciadas como experiencias extremadamente violentas" (Becerra y Altimir, 2012, p. 205). En síntesis, la violencia de la que huyen los migrantes forzados se reproduce en el contexto de inmigración, donde los procesos de inserción a la sociedad de acogida son vividos de manera violenta.

\section{Reflexiones de cierre}

Frente a las experiencias presentadas, nos preguntamos acerca de qué motiva a las mujeres colombianas a permanecer en un lugar donde son maltratadas y humilladas. Y aquí es donde el concepto de migración forzada se impone con todas sus connotaciones en nuestras reflexiones. Asimismo, aparece el sentimiento de seguridad, lo que marca la diferencia para estas mujeres que viniendo a Chile escapan de otro tipo de violencia.

Dentro de todas las categorías evaluadas en el Diagnóstico Participativo, vimos que el acceso a la salud y la sensación de seguridad son de los pocos aspectos positivos de la experiencia como solicitantes de asilo en Iquique y que, en general, las condiciones de vida, así como de convivencia con la sociedad chilena y sus instituciones, están marcadas por experiencias de discriminación y violencia. Ante esto, nos surge otra reflexión: la discriminación, la estigmatización, el hostigamiento y la violencia racista representan un grave problema cultural y social, del que tanto el Estado como la sociedad civil deben hacerse cargo y buscar soluciones. Estas conductas dan cuenta de que la población nacional es altamente violenta $y$ que encontró en este grupo una alteridad absoluta a la que deshumaniza ("Mono, querís manî"), al punto de tratarla literalmente como animal, recordándonos tristes episodios de la colonización.

Si bien en el ámbito de la salud las mujeres manifestaron una apreciación positiva, son conocidos los casos en Chile que refieren a dificultades en el acceso o en la atención en salud (Becerra y Altimir, 2012; Courtis, 2012; Valenzuela, 2009). Asimismo, existen muchas tareas pendientes en materia laboral (facilidades de visas y permisos de trabajo), en cuanto a la legislación laboral y su aplicación; en el acceso a la educación, así como a la vivienda y regulación del mercado inmobiliario. Esto, en palabras de Bijit, "resalta la inexistencia de políticas públicas y programas estatales orientados hacia la integración de los inmigrantes y refugiados en los diversos ámbitos de la vida social, cultural, económica y política" (Bijit Abde, 2012, p. 178). Por tanto, parece inoportuno que Chile se autoproclame "país de acogida", ${ }^{20}$

20 En Instructivo presidencial No 9 de 2008. 
cuando las condiciones de vida de estas personas están demostrando la deslegitimación del refugio.

Específicamente lo que sucede en la frontera es ejemplar. Nuestra conclusión es que la PDI, a cargo del control migratorio, sigue los lineamientos de la Ley de Extranjería, sospechando de todo extranjero que solicite asilo. Los hechos demuestran que en estos controles existen prácticas arbitrarias y racistas que conllevan al "rebote" y que no dejan de reproducirse, a pesar de constatar una disminución (Liberona, 2015b). Así, se perpetúan los ingresos irregulares en el caso de las migraciones forzadas, produciéndose mayor desprotección, con los riesgos que esto implica, entre otros, el de no ser reconocidos como solicitantes de asilo y tener que permanecer en clandestinidad. Para subsanar esta situación, se requiere con urgencia una nueva Ley de Migraciones que extirpe el principio de la seguridad nacional y otorgue verdaderamente el derecho a migrar, limitando la discrecionalidad de los funcionarios a cargo del control migratorio.

En cuanto al programa en sí, nuestra reflexión es que en lugar de generar las condiciones para el desarrollo integral de las personas en el nuevo contexto donde se instalan, construyen un perfil de personas "asistidas". Es decir, que la asistencia humanitaria en vez de proporcionar dignidad a las personas las conduce a la dependencia, la reproducción de problemas sociales y el inmovilismo político. La imposibilidad de pronunciar la palabra "trabajo", ya que esto implicaría quedar fuera del proceso de solicitud de asilo es una demostración clara de la perversidad del sistema. Marx (1973 [1872]) evidenció que el concepto de trabajo va más allá de su dimensión puramente económica y explicó cómo se convierte en una categoría antropológica, es decir, constituyente del ser humano. Por tanto, desincentivar el acceso al trabajo de alguna manera desarticula la humanidad de estas personas, al generar dependencia económica y/o trabajo informal e incluso abuso laboral.

Entonces, si bien la Ley de Refugio es concebida para cumplir con los estándares internacionales del sistema humanitario y de esta manera brindar mayor protección y un mejor despliegue intersectorial, a la vez hemos visto que en el caso estudiado no se dan las condiciones para alcanzar esos objetivos.
Nos preguntamos si esto responde a una crisis internacional del sistema de protección humanitaria, ya que mientras mayores son las exigencias y más los avances ${ }^{21}$ se producen menos soluciones duraderas y dignas para los migrantes forzados. ¿Dónde está el nudo de tantos sinsentidos? ¿Será, como plantea Naranjo (2015), en el orden fronterizo de las cosas? ¿O como lo plantea Fassin (2010), quien analiza la tensión entre la justicia social y la razón humanitaria, cuyo principio es éticamente aceptado a nivel internacional y avalado por los derechos humanos, pero en cuya acción se reproducen las desigualdades sociales? Por tanto, siguiendo a Fassin, se legitima el derecho a la vida invisibilizando las desigualdades sociales e impidiendo que se tomen como un mismo fenómeno. En este caso, podemos pensar que lo que importa éticamente es tener una ley de refugio para cumplir con los estándares internacionales, sin embargo lo que sucede en la vida de las personas es que continúan experimentando injusticias.

En conclusión, los estigmas sobre la población colombiana se suman a la dificultad de ser un migrante forzado, muchas veces no reconocido, "rebotado", "rechazado", "negado", "clandestino". Y con esto, retomamos la discusión sobre la crisis del sistema humanitario internacional, cuya principal expresión es no lograr dar cumplimiento al principio de protección a aquellos migrantes, que se consideran ellos mismos "forzados". Ramírez plantea que la sociedad colombiana entera se encuentra expuesta a un régimen de víctima "reconociéndose como sujetos de masacre, crimen y tragedia por parte del Estado, paramilitares y/o guerrillas" (Ramírez, 2011, p. 162). En este sentido, es interesante considerar la propuesta analítica de Naranjo, quien llama a "conceptualizar el nexo migración-desplazamiento-asilo en el orden fronterizo de las cosas" (2015, p. 278). Es decir, incorporar el debate de la complejidad de las causas

21 Desde el año 2014 en adelante se han producido significativos avances en materia migratoria en Chile, marcando un giro en la política migratoria, basado en dos instructivos presidenciales: el No 9 del año 2008 y el No 5 del año 2015. A partir de estas instrucciones, se dio paso a importantes modificaciones al Reglamento de Extranjería, así como a la protección de derechos a la salud, la identidad y la educación, principalmente. Aun así, la demanda por un nuevo marco jurídico sigue sin respuesta. 
de las migraciones actuales, como parte de las transformaciones sociales transnacionales, para lo cual el concepto de migración forzada permite incluir a migrantes, desplazados y refugiados en los mismos procesos migratorios. Por este motivo, vemos con preocupación la disminución de la concesión del estatus de refugiado en Iquique, ya que una parte importante de los inmigrantes colombianos, ya sea que solicite o no el asilo una vez que ha llegado a la ciudad, viene de alguna manera huyendo de una situación invivible, en la que sus derechos humanos han sido reiteradamente vulnerados. La condición de refugiado que sostiene el sistema humanitario internacional no se condice por tanto con la realidad y complejidad de los fenómenos contemporáneos.

\section{Referencias citadas}

ACNUR (2007). Migración forzada y desarrollo. Paper presented at the Foro Global sobre Migración y Desarrollo.

Agier, M. (2006). Le gouvernement humanitaire et la politique des réfugiés. En Cornu, L. y Vermeren, P. (Eds.). La philosophie déplacée: Autour de Jacques Rancière, Colloque de Cerisy. Paris: Horlieu Editions.

Altimir, L. y Becerra, M. (2012). El derecho a la salud de los niños y niñas migrantes y refugiados, contextos y especificidad en salud mental. Los derechos de los niños, niñas y adolescentes migrantes, refugiados y victimas de trata internacional en Chile. Avances y desafios (pp. 191-216). Santiago de Chile: ACNUR/OIM/UNESCO.

Amador, M. (2011). La incesante diáspora africana: afrocolombianas solicitantes de asilo en el norte chileno. Revista Nomadias, 12. Sección Campo abierto, 89-103.

Amstein, D. (2012). Voces ocultas: Refugiados Palestinos en Chile. Tesis para optar al título de Antropólogo y al grado de Licenciado en Antropología, Universidad Academia de Humanismo Cristiano, Santiago de Chile.

Bassa, J. y Torres, F. (2015). Desafíos para el ordenamiento jurídico chileno ante el crecimiento sostenido de los flujos migratorios. Estudios Constitucionales, 2, Año XIII, 103-124.

Bijit Abde, K. (2012). El proceso de integración social de los refugiados palestinos reasentados en región de Val- paraíso, Chile. Si Somos Americanos. Revista de Estudios Transfronterizos, XII(1), 155-180.

Castles, S. (2003). Towards a Sociology of Forced Migration and Social Transformation. Sociology, 77(1), 13-34.

Contreras, Y., Veera, A.-L. y Labbé, G. (2015). Acceso exclusionario y racista a la vivienda formal e informal en las áreas centrales de Santiago e Iquique. Polis. Revista Latinoamericana, 42. Retrieved from http://polis.revues. org/11266

Convención sobre el estatuto de los refugiados (1951).

Courtis, C. (2012). Niños, niñas y adolescentes refugiados/ as en Chile: un cuadro de situación. Los derechos de los niños, niñas y adolescentes migrantes, refugiados y víctimas de trata internacional en Chile. Avances y desafios (pp. 159190). Santiago de Chile: ACNUR/OIM/UNICEF.

Declaración de Cartagena sobre refugiados (1984).

DEM (2016). Migración en Chile 2005-2014. Santiago de Chile: Departamento de Extranjería y Migración del Ministerio del Interior y Seguridad Pública. Sección Estudios. Recuperado de http://www.extranjeria.gob. cl/media/2016/02/Anuario-Estad\%C3\%ADsticoNacional-Migraci\%C3\%B3n-en-Chile-2005-2014. pdf.

Fassin, D. (2010). El irresistible ascenso del derecho a la vida. Razón humanitaria y justicia social. Revista de Antropología Social, 19, 191-204

Geulen, C. (2010). Breve historia del racismo. España: Alianza.

González, A. (2015). Del desplazamiento forzado interno en Colombia a la migración transfronteriza hacia Ecuador. [From Forced Internal Displacement in Colombia to Cross-Border Migration to Ecuador]. Estudios Politicos, 47, 177-197. doi:10.17533/udea.espo.n47a11

González, S. (2004). El dios cautivo. Las ligas patrióticas en la chilenización compulsiva de Tarapacá (1910-1922). Santiago: LOM.

Gzesh, S. (2008). Una redefinición de la migración forzosa con base en los derechos humanos. Migración y Desarrollo, Primer semestre, 97-126. 
Liberona, N. (2012). De la alterisación a la discriminación en un sistema público de salud en crisis: conflictos interétnicos a propósito de la inmigración sudamericana en Chile. Revista de Ciencias Sociales, 28, 19-38. Universidad Arturo Prat.

Liberona, N. (2015a). De las fronteras geopolíticas a las fronteras sociales: La migración boliviana a través de la prensa de Tarapacá (1990-2007). [From geopolitical borders to social boundaries: Bolivian migration through the Tarapacá press (1990-2007)]. Estudios fronterizos, 16(32), 41-74. Retrieved from <Go to ISI>:// SCIELO:S0187-69612015000200002

Liberona, N. (2015b). La frontera cedazo y el desierto como aliado. Prácticas institucionales racistas en el ingreso a Chile. Polis. Revista Latinoamericana, 42.

Marx, K. (1973 [1872]). El Capital. Crítica de la economía politica. Libro primero (Vol. 1). México: Fondo de Cultura Económica.

Naranjo, G. (2015). El nexo migración-desplazamientoasilo en el orden fronterizo de las cosas. Una propuesta analítica. [The Nexus Migration-Displacement-Refuge in the Order of Things at the Border. An Analytical Approach]. Estudios Políticos, 47, 265-284. doi:10.17533/ udea.espo.n47a15

Pavez, J. (2016). Racismo de clase, racismo de género: “mujer chilena", "mestizo blanquecino" y "negra colombiana" en la ideología nacional chilena. En Tijoux, M. E. (Ed.). Racismo en Chile. La piel como marca de la inmigración (pp. 227-242). Santiago de Chile: Universitaria.

Ramírez, C. (2011). Refugiados colombianos en Chile. Éxodo del conflicto armado. Tesis para optar al título profesio- nal de Sociólogo, Universidad Academia de Humanismo Cristiano, Santiago de Chile.

Riaño, P. (2009). Desplazamiento interno en Medellín y refugio de colombianos en Ecuador. Controversia, 193, 47-85.

Stefoni, C. (2011). Ley y política migratoria en Chile. La ambivalencia en la comprensión del migrante. En Feldman-Bianco, B., Rivera Sánchez, L., Stefoni, C. y Villa Martínez, M. I. (Eds.). La construcción social del sujeto migrante en América Latina. Prácticas, representaciones y categorias (pp. 79-109). Quito: CLACSO, FLACSO Sede Ecuador, Universidad Alberto Hurtado. FLACSO Serie Foro, CLACSO Colección Cátedra Iberoamericana de Estudios sobre Migraciones.

Subercaseaux, B. (2007). Raza y nación: el caso de Chile. $A$ Contra corriente, 5(1), 29-63.

Tijoux, M. E. (2014). El Otro inmigrante "negro” y el Nosotros chileno. Un lazo cotidiano lleno de significaciones. Boletin Onteaiken, 17.

Tijoux, M. E. (2016). Racismo en Chile. La piel como marca de la inmigración. Santiago de Chile: Universitaria.

Tijoux, M. E. y Palominos, S (2015). Aproximaciones teóricas para el estudio de procesos de racialización y sexualización en los fenómenos migratorios de Chile. Polis. Revista Latinoamericana, 14(42). Recuperado de http:// polis.revues.org/11351

Valenzuela, I. (2009). Diagnóstico de la Población Colombiana en la Frontera Norte de Chile. Inédito.

Villa, M. I. (2009). Migración forzada: la otra cara de la migración internacional. El caso de colombianos en Ecuador. Controversia, 193, 11-45. 